\title{
A single centre retrospective review of colorectal cancer in trinidad over a three year period
}

\author{
Abstract \\ Aim: To determine the demographics of patients with endoscopic diagnosis of colorectal \\ cancer and the site of lesion. \\ Method: A retrospective study of endoscopic diagnosis of colorectal cancer in 118 patients \\ at the Port-of-Spain General Hospital. \\ Results: The mean age of patients was $65.53 \%$ of patients were female. Only $5 \%$ of \\ patients were below the age of 40 . Left-sided tumors were more common than right-sided \\ ones. The main reasons for referring the patient for a lower GI endoscopy was suspected \\ cancer, GI bleed and anemia. \\ Conclusion: At this time no screening programme exists in Trinidad and Tobago. Screening \\ will aid in identification and removal of precancerous polyps and cancerous lesions at an \\ early stage which will improve patient survival.
}

Volume 8 Issue I - 2017

\author{
Marcus K Rampersad, Saeeda R Mohammed, \\ Ricardo Jurawan \\ Department of Medicine, Port-of-Spain General Hospital, \\ Trinidad
}

Correspondence: Ricardo Jurawan, Department of Adult Medicine, Port-of-Spain General Hospital Upper Charlotte Street, Port-of-Spain, Tel I-868-7|3-2|88,

Email ricardo.jurawan@gmail.com

Received: June 04, 2017| Published: November 10, 2017

\section{Abbreviations: GI, gastrointestinal; CRC, colorectal cancer \\ Introduction}

Colorectal cancer (CRC) is listed as the third most common cancer globally and accounts for $9.7 \%$ of all cancers (excluding nonmelanoma skin cancer). It is listed as the third most common type of cancer in men and the second most common in women. ${ }^{1}$ Colorectal cancer represents the fourth most common cause of cancer death worldwide. ${ }^{2}$ According to the PAHO 2013 report, it is a growing burden in Latin America and the Caribbean. In Trinidad \& Tobago it is the third most common type of cancer (12\%) in men and women $(11 \%) .{ }^{3}$ Increasing age has been listed as a risk factor for CRC. ${ }^{4}$ The likelihood of diagnosis of CRC increases after the age of $40 .{ }^{5}$ The National Cancer Institute SEER cancer statistics review shows that in excess of 90 percent of cases of colorectal cancer are found in patients over the age of 50 in a US population. ${ }^{6}$ However, this registry predicts that there will be a $90 \%$ increase in the rate of colon cancers in persons 20-39 years and a $124 \%$ increase in rectal cancers by 2030. There are gender differences in CRC. The incidence of CRC is higher in females than in males, when considering persons older and 65 years. ${ }^{7,8}$ The 5-year survival rate for colorectal cancer in females, over the age of 70, is higher than that for males. ${ }^{7}$ In a review of the literature it was found that patients with right-sided CRC were more likely to be female, have poorly differentiated tumors and present with larger tumors. ${ }^{9}$ A German study found that patients with right-sided colon cancer also tended to present with vague symptoms and this was associated with later presentation and more advanced stage at presentation ${ }^{10}$ One United States study has shown an increase in right compared to left-sided lesions. ${ }^{11}$

\section{Materials and methods}

This is a retrospective study of all cases of colorectal cancer identified by endoscopy at the Port-of-Spain General Hospital in North Trinidad. Permission to conduct this study was granted from the Medical Director at the institution.

A. Inclusion criteria: All endoscopy reports over a three year period from January 2012 to December 2015 were included in the study if the overall appearance was suggestive of a malignant lesion.
B. Exclusion criteria: Polyps and lesions that appeared benign at endoscopy were excluded.

Data were collected to determine the reason for referral for lower gastrointestinal endoscopy and the site of the lesion Right-sided lesions were taken as those that were found in the ascending colon, including the caecum, and up to the proximal half of the transverse colon. Left-sided lesions were taken as the distal half of the transverse colon, the descending and sigmoid colon and rectum. Demographic information was collected. The data was analyzed using Microsoft Excel and SPSS Version 22.

\section{Results and discussion}

A total of 118 cases of suspected colorectal cancer were identified on lower gastrointestinal endoscopy during the period January 2012 to December 2015. Females accounted for 63 cases (53\%) (Figure 1). The average age at diagnosis was 64.8 years, with $29.5 \%$ of all cases occurring in the seventh decade of life (Figure 2). With respect to site of lesion, left-sided lesions were more common (73\%) (Figure 3) with rectal lesions being found in $46 \%$ of cases. Lesions of the ascending colon, including the caecum, were found in $27 \%$ of cases. The three main causes for referral for colonoscopy were suspected colorectal cancer, gastrointestinal bleeding and anaemia (Figure 4).

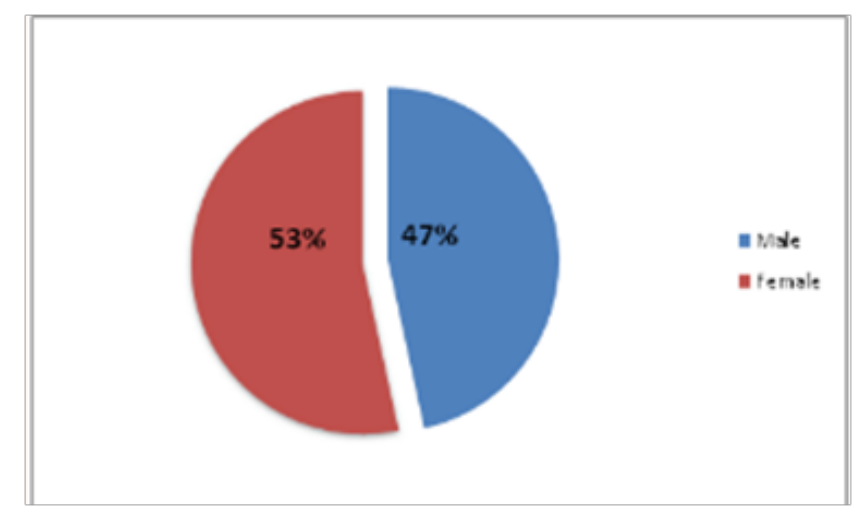

Figure I Gender distribution of patients.

$\mathrm{N}=118$ 


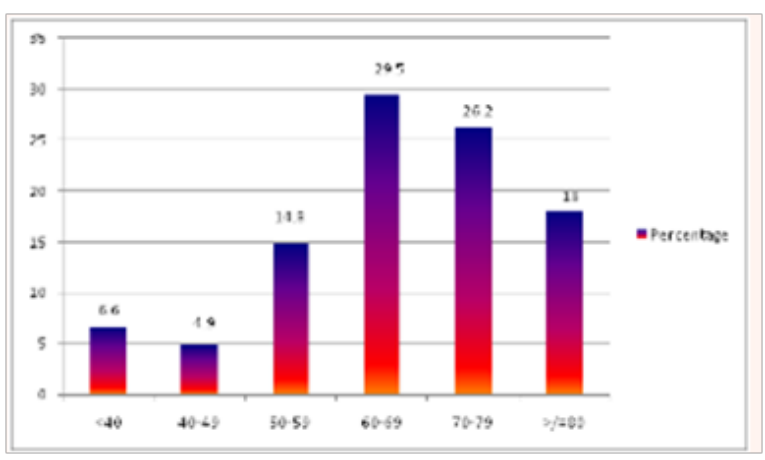

Figure 2 Age of patient at diagnosis. Mean: 64.87

SD: 14.08

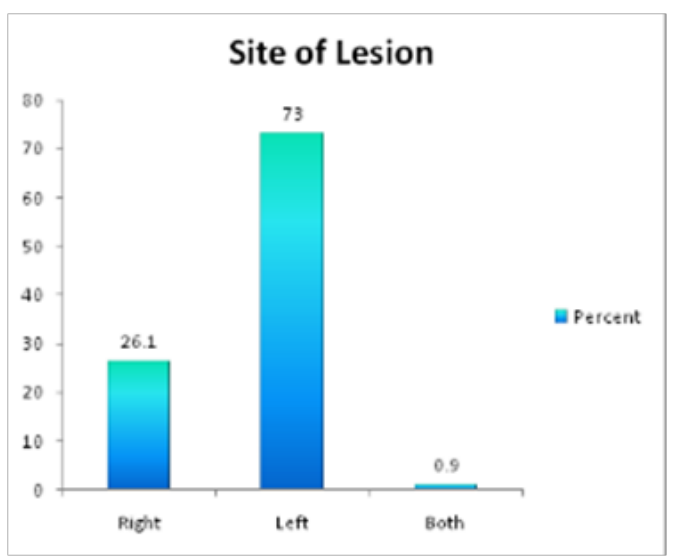

Figure 3 Site of CRC lesion.

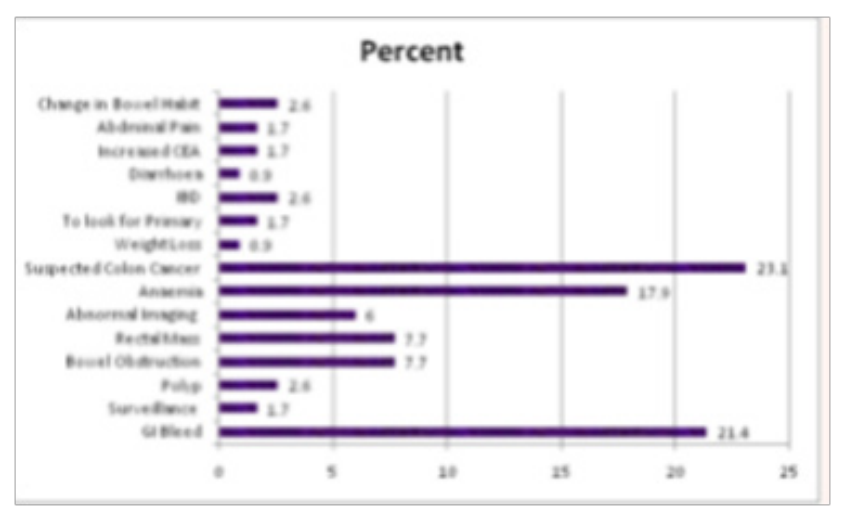

Figure 4 Indication for colonoscopy.

In this study females were found to account for more suspected cases of colorectal cancer than males. It has been found in previous studies that the incidence of CRC was more common in females than males, in older persons (more than 65 years). ${ }^{7,8}$ The average age of persons in this study was 65 . The older age of the patients in this study reflects that found in prior studies where the incidence of $\mathrm{CRC}$ was found to increase with age. ${ }^{4-6}$ Risk factors for CRC include increasing age, familial and life-style related factors- such as smoking, sedentary lifestyle, obesity, alcohol use, high consumption of animal fats and red meat. There is an increased risk with a personal history of adenomatous polyps and inflammatory bowel disease as well as a family history of adenomatous polyps and colorectal cancer. ${ }^{5}$ In terms of diet and its association with colorectal cancer, countries that consume more red meat, processed meats, animal fats and refined carbohydrates have been shown to have an increased risk of colorectal cancer. In developed nations like North America and Europe where large amounts of these are consumed the incidence of colorectal cancer is higher than less developed countries like Africa, rural India, parts of South America and Japan where a more plant-based diet is consumed. ${ }^{12,13}$ The risk factors for colorectal cancer have not been investigated in Trinidad and Tobago. A population study is needed to further investigate the incidence, mortality and risks of colorectal cancer in this country. This is important because screening may then be implemented in higher risk groups such as those with central obesity, strong smoking history and significant alcohol consumption even at a younger age. ${ }^{14}$

There are already some primary cancer prevention policies in Trinidad and Tobago. ${ }^{15}$ With respect to tobacco use, all public places are now smoke free zones. The tax for tobacco has been raised by $15 \%$ in the 2016 budget and that for alcohol has been raised by $20 \%{ }^{16}$ However more can be done as there is no policy on inserting warning labels on the package of cigarettes and there is no ban on advertising and promoting cigarettes use in the media. A policy for weight loss for reducing overweight/obesity as a form of primary cancer prevention was generated in $2012 .{ }^{15}$ Swedish ${ }^{17}$ and US ${ }^{11}$ studies have suggested an increase in the diagnosis of right-sided lesions. This may be due to better screening practices. Right-sided lesions tend to present later because the symptoms are usually non-specific such as weight loss and symptoms of anaemia while left-sided lesions present with per rectum bleeding, altered bowel habit and tenesmus. ${ }^{18}$ One regional, population-based study in Martinique also showed a increase in incidence of right-sided lesions. ${ }^{19} \mathrm{~A}$ robust screening programme will help in the early detection of right-sided lesions from early diagnosis and treatment.

\section{Conclusion}

Limited data exists for Trinidad and Tobago with respect to colorectal cancer. The cancer registry is up to date only until 2002 with no information in terms of risk factors for cancer such as dietary consumption of meat, fruit and vegetables, alcohol consumption and physical activity. The incidence of colorectal cancer and mortality from it is not known. A population study is definitely needed at this time to ascertain this data. At this time no screening programme exists in Trinidad and Tobago. It is imperative to have a good screening programme as screening can identify precancerous polyps at an asymptomatic stage so that they may be removed. Screening can also detect cancers at an early stage when treatment is more effective and survival is improved. ${ }^{20}$ The American Cancer Society recommends screening of all persons over the age of 50 years who have an average risk of developing colorectal cancer with colonoscopy every 10 years or CT colonoscopy every 5 years or flexible sigmoidoscopy every 5 years or double contrast barium enema every 5 years- with colonoscopy being done if the latter 3 tests are positive ${ }^{21}$ In the ideal setting these recommendations would be effected but currently it is difficult to achieve as there is only one gastroenterologist servicing the public sector of Trinidad and Tobago. In order to implement a proper screening programme there is need to increase the manpower in gastroenterology, especially in the public sector.

\section{Conflicts of interest}

No financial or conflict of interest exists within this research article. 


\section{Acknowledgements}

None.

\section{References}

1. Ferlay J, Soerjomataram I, Ervik M, et al. Cancer Incidence and Mortality Worldwide: IARC CancerBase No. 11 [Internet]. Int J Cancer. 2014;136(5):E359-E386.

2. http://www.who.int/mediacentre/factsheets/fs297/en/

3. http://new.paho.org/panamericanforum/wp-content/uploads/2013/10/ Cancer-Country-Profiles-2013-ENG.pdf

4. http://www.cdc.gov/cancer/colorectal/statistics/age.htm

5. Haggar FA, Boushey RP. Colorectal Cancer Epidemiology: Incidence, Mortality, Survival, and Risk Factors. Clinics in Colon and Rectal Surgery. 2009;22(4):191-197.

6. Ries LAG, Melbert D, Krapcho M, et al. SEER Cancer Statistics Review, 1975-2005. Bethesda, USA. National Cancer Institute; 2005.

7. Kim SE, Paik HY, Yoon H, et al. Sex- and gender-specific disparities in colorectal cancer risk. World J Gastroenterol. 2015;21(17):5167-5175.

8. Ferlay J SI, Ervik M, Dikshit R, et al. GLOBOCAN 2012 v1.0, Cancer Incidence and Mortality Worldwide: IARC Cancer Base No. 11. Lyon, France. International Agency for Research on Cancer; 2013.

9. Hansen IO, Jess P. Possible better long-term survival in left versus rightsided colon cancer - a systematic review. Dan Med J. 2012;59(6):A4444.

10. Benedix F, Kuber R, Meyer F, et al. Comparison of 17,641 patients with right- and left-sided colon cancer: differences in epidemiology, perioperative course, histology, and survival. Dis Colon Rectum. 2010;53(1):57-64.
11. Jessup JM, McGinnis LS, Steele GD Jr, et al. The National Cancer Data Base. Report on colon cancer. Cancer. 1996;78(4):918-926.

12. Lipkin M. Dietary, Environmental and Hereditary Factors in the Development of Colorectal Cancer. Cancer Journal for clinicians. 1979;29(5):291-298.

13. Norat T, Lukanova A, Ferrari P, et al. Meat consumption and colorectal cancer risk: Dose-response meta-analysis of epidemiological studies. Int J Cancer. 2002;98(2):241-256.

14. Eun Lee S, Bum Jo H, Gun Kwack W, et al. Characteristics of and risk factors for colorectal neoplasms in young adults in a screening population. World J Gastroenterol. 2016;22(10):2981-2992.

15. http://www.paho.org/hq/index.php?option=com_docman\&task=doc view\&gid $=23013 \&$ Itemid $=270$ \&lang $=$ en

16. http://www.guardian.co.tt/news/2016-10-20/new-alcohol-tobaccoonline-taxes-start-today

17. Thörn M, Bergström R, Kressner U, et al. Trends in colorectal cancer incidence in Sweden 1959-93 by gender, localization, time period, and birth cohort. Cancer Causes \& Control. 1998;9(2):145.

18. Richman S, Adlard J. Left and right sided large bowel cancer : Have significant genetic differences in addition to well known clinical differences. BMJ. 2002;324(7343):931-932.

19. Joachim C, Véronique-Baudin J, Razanakaivo M, et al. Trends in colorectal cancer in the Caribbean: A population-based study in Martinique, 1982-2011. Rev Epidemiol Sante Publique. 2017;65(3):181188 .

20. http://www.cdc.gov/cancer/colorectal/sfl/

21. https://www.cancer.org/cancer/colon-rectal-cancer/detection-diagnosisstaging/acs-recommendations.html 